\title{
E-commerce online review for detecting influencing factors users perception
}

\author{
Irvan Krisna Arsad, Djoko Budiyanto Setyohadi, Paulus Mudjihartono
}

Informatics Department, Universitas Atma Jaya Yogyakarta, Yogyakarta, Indonesia

\begin{tabular}{|c|c|}
\hline Article Info & ABSTRACT \\
\hline Article history: & To date, online shopping using e-commerce services becomes a trend. The \\
\hline Received Aug 3, 2020 & emergence of e-commerce truly helps people to shop more effectively and \\
\hline Revised May 4, 2021 & commerce, especially from the user perspective. This research aims to explore \\
\hline Accepted Oct 24, 2021 & $\begin{array}{l}\text { user review data, particularly on factors that influence user perception of e- } \\
\text { commerce applications, classify, and identify potential solutions to finding }\end{array}$ \\
\hline Keywords: & $\begin{array}{l}\text { problems in e-commerce applications. Data is grabbed using web scraping } \\
\text { techniques and classified using proper machine learning, i.e., support vector }\end{array}$ \\
\hline Digital marketing & machine (SVM). Text associations and fishbone analysis are performed based \\
\hline E-commerce & on the classified user review data. The results of this study show that the user \\
\hline Sentiment analysis & $\begin{array}{l}\text { satisfaction problem can be captured. Furthermore, various services that } \\
\text { should be provided as a potential solution to experienced customers' problems }\end{array}$ \\
\hline Text association & or application users' perception problems can be generated. A detailed \\
\hline Text mining & discussion of these findings is available in this article. \\
\hline
\end{tabular}

This is an open access article under the CC BY-SA license.

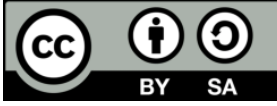

Corresponding Author:

Djoko Budiyanto Setyohadi

Informatics Department

Universitas Atma Jaya Yogyakarta

Jl. Babarsari 43 Yogyakarta 55281, Indonesia

Email: djoko.budiyanto@uajy.ac.id

\section{INTRODUCTION}

The internet allows users to make online reviews on various types of platforms. In addition to sharing personal experiences, users also show their emotions or feelings in user-generated content (UGC), such as user reviews [1]. The sentiment polarity in online reviews reflects user perceptions about the various services available [2]. Also, potential customers who read online reviews can be significantly affected by the sentiment polarity of the reviews listed in the review column [3], [4]. It indicates that users' positive and negative sentiment comments significantly affect other users choosing the service or product sought [5]. Electronic commerce (e-commerce) has become a new trend in online shopping [6]. On e-commerce platforms, reviews allow users to evaluate and compare other alternatives before making more advanced decisions. Therefore, a product service review is considered a driver for increasing users' usability and future attractiveness [7], [8]. The review can also provide information in the form of factors that influence the user's perception in doing a review related to feelings of pleasure or disappointment with the service or product used; this can help the developer capture and pay attention to customers and focus on the main problem, thereby increasing service quality and increase customer satisfaction [1].

Technology is important aspect in acceptance model and it should be more elaborated [9]. Rely on that approach, the most significant competition occurs from three e-commerce businesses in Indonesia, namely e-commerce 1 , e-commerce 2 , and e-commerce 3 are selected. The three of them into the most favorite e-commerce indicators with the most accessed, most frequently purchased, and recommended e- 
commerce. One of them is shown in terms of the ranking obtained in the Google Play Store, e-commerce 1 ranks first with a total monthly visitor of 71,533,300 users, ranked second by e-commerce 2 with a total monthly visitor of $69,800,000$ users, and e-commerce 3 occupies the third rank with total monthly visitors of $37,633,300$ users. From this percentage, this research will use e-commerce applications, namely e-commerce 1, e-commerce 2, and e-commerce 3 in the Google Play Store as a case study.e-commerce applications, namely e-commerce 1 , e-commerce 2 , and e-commerce 3 , offer many conveniences, but they do not necessarily make users feel satisfied. Sometimes a system also has a weakness contained therein. So we need to make improvements that need to be done on the application concerning performance [10]. Through the reviews written by application users, there is expected feedback, but with so many data reviews coming in, the e-commerce application system has not been able to know what things need to be done to improve. There is no systematic method that is so appropriate to classify a review into positive and negative groups [11].

Classification of user review data based on sentiment will help the developer get a perception of information from e-commerce application users. This study will compare the sentiments obtained with other e-commerce application sentiments, namely e-commerce 1 , e-commerce 2 , and e-commerce 3 . It is expected that e-commerce 1, e-commerce 2, and e-commerce 3 applications can make improvements over time to improve service quality and increase customer satisfaction. The classification process is carried out by machine learning with the support vector machine (SVM) method. Data review exploration uses descriptive statistical methods and text associations to look for related words so that later in the process, there are factors that can influence user perception. SVM is a classification algorithm developed from the hyperplane concept. The idea is that this hyperplane will separate a big group of data in a hyperspace into several smaller groups. SVM is a linear classification; the optimization of how the group is classified is done by transforming the plane in the higher dimensional space. This condition makes the dimension of vector input insignificantly influence the SVM. Therefore the optimization process will go smoothly even though the data are limited, just like in text processing. The existing research shows that SVM deals with data limitations. Furthermore, $t$ it is convinced that SVM is a potential alternative for solving the text review classification problem in the online review e-commerce [12]-[14].

Previous research also shows that SVM is powerful in dealing with the dimension problem of classification. Previous researchers try to investigate customer satisfaction with a marketplace, their research compares two methods, namely SVM and naïve bayes classifier (NBC), as a classification technique with TF-IDF weighting. The results showed that SVM with linear kernels provides higher accuracy than NBC. SVM shows an accuracy of 93.65\%, while NBC receives 89.28\% [15]. In 2020, Vijayaragavan et al. [16] used the SVM method to conduct sentiment analysis on product reviews, with a dataset of 1811 reviews of iPod reviews. In this study, the SVM method gets an accuracy of $96.57 \%$ compared to other methods such as radial basis function (RBF) network, which only gets $88.84 \%$, R.F. gets $88.34 \%$, D.T. gets $86.01 \%$, and MLP gets $85.31 \%$. In this study also SVM projected that the level of sensitivity and specifications are projected to be superior among all methods available in classifying a given iPod dataset [16]. In a study conducted by Setyohadi et al. [17] with the title "Galvanic skin response data classification for emotion detection". One method used is the SVM and preprocessing to validate the galvanic skin response (GSR) data. Receiver operating characteristic (ROC) curves and accurate measurements are used to verify the proposed approach. Their method shows that the accuracy is around $75.65 \%$, while the ROC is about 0.8019 . It means that emotional detection can be done satisfactorily and done well.

The research, entitled "Comparative study of machine approaches for amazon reviews" was researched in order to examine the efficiency of three methods of machine learning, namely SVM, NBC, and maximum entropy (M.E.) [11]. It classifies online reviews on Amazon's marketplace. The results showed that the SVM produced a high accuracy value [10]. Research of sentiment analysis on mobile application health located in the Google Play Store and App Store. This study found 88125 reviews online from 104 health applications found on the Google Play Store and App Store. The algorithm is used in machine learning using one method, SVM [18]. Sentiment analysis about Twitter was conducted by Suganthi and Geetha [19] relating to the goods and service tax (GST) about India's tax system. Tweets are classified into positive, negative, and neutral tweets based on sentiment by classifying the dataset using various SVM algorithms. Sentiment analysis in R by calculating sentiment scores for each tweet [19]. In the other study, the sentiment analysis of capital relocation discourse is also performed [20]. Their research compared several algorithms used: naïve bayes classifier, logistic regression, SVM, and K closest neighbors. The results showed that the SVM outperformed compared with three algorithms with accuracy, precision, recall, and F-measuring $97.72 \%, 96.01 \%, 99.18 \%$, and 97.57\%, respectively. Regarding previous scholar and characteristics data, especially the vector input dimension on text processing, dealing with that problem, we propose using SVM. 


\section{RESEARCH METHOD}

\subsection{Data collection}

The detailed research method can be seen from Figure 1. The applying research type is qualitative analysis, which performs dataset analysis in the form of "words" as running text preprocessing. Additionally, the data source is secondary data taken from the Google Play Store website. Web scraping techniques are used to get user reviews from the comments or reviews in e-commerce 1, e-commerce 2, and e-commerce 3 mobile e-commerce applications. The dataset is built from 14,270 online reviews.

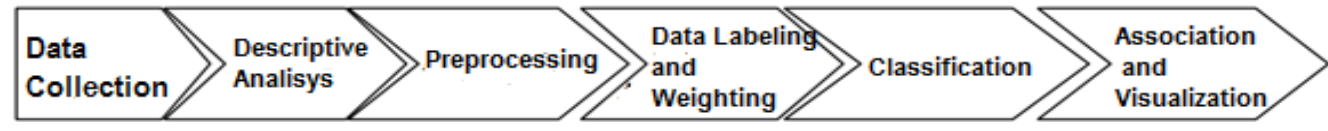

Figure 1. The research method

\subsection{Descriptive analysis}

Before entering the preprocessing stage, the data obtained using the scraping method will be analyzed in advance about the number of reviews and ratings available on e-commerce 1, e-commerce 2 , and e-commerce 3 e-commerce [21]. Descriptive analysis results will be visualized to know three e-commerce sites [22], [23].

\subsection{Preprocessing data}

This process is the stage carried out to transform data from unstructured data into structured data so that it is easy to analyze further. The steps are taken is being as [19]:

- The process of cleaning documents (cleaning) is cleansing characters such as HTML, hashtag, site address (HTTP: www /site.com), the username (@username), punctuation such as (.,!? [] /\% ;: 〈> ()), number $(0,1,2,3,4,5,6,7,8,9,0)$ and other characters besides the alphabet;

- Normalization is the stage where the process of correcting misspelled words or abbreviated words;

- Case-folding is the process of changing letters into one form in one text document, for example, changing from a capital form to lowercase or vice versa, ranging from A to Z;

- Tokenizing is a process of separating the text into pieces of words called tokens. The purpose of this process is to get the words that will be entities that have value in the matrix of the text document to be analyzed; (5) filtering/stopword removal is a process of eliminating unnecessary words such as conjunctions, pronouns, and the selection of meaningful words using the stopword algorithm;

- Stemming is a stage of changing words into essential words by removing affixes, inserts, suffixes, and a combination of beginning and end on derived words in the review.

\subsection{Data labeling and weighting}

After the data goes through the preprocessing stage, the words' data are then converted into vectors, then given a value and weighting for each word by using term frequency-inverse document frequency (TFIDF). TF-IDF is frequently used because it is relatively simple, but it can generate high accuracy and recall [24]. IDF value is calculated using (1).

$$
i d f_{i}=\log \left(\frac{D}{d f_{i}}\right)
$$

where; D: Number of all documents in the collection, and

$D f_{i}$ : Number of documents containing the term $t_{j}$.

TF-IDF valuesare calculated using (2).

$$
w_{i j}=t f_{i j} \times i d_{j}
$$

where; $w_{i j}$ : The weight of the term $t_{j}$ for the document $d_{i}$

$t f_{i j}$ : Number of occurrences of the term $t_{j}$ in the $d_{i}$ document

$d f_{I}$ : Number of documents containing term $t_{j}$

\subsection{Classification}

After preprocessing and vectorizing text data, classification is performed using the SVM algorithm. SVM's concept can be explained only as an attempt to find the best hyperplane that functions as a separator 
of two classes in the input space [12]. SVM tries to find a separating function (hyperplane) by maximizing the distance between classes [25]. In this way, SVM can guarantee high generalization capabilities for future data. The illustration of SVM is shown in Figure 2. The research uses four kernels as a comparison to get the best results from one of those kernels [26]. Furthermore, the kernel to be tested is linear, polynomial, RBF, and sigmoid.

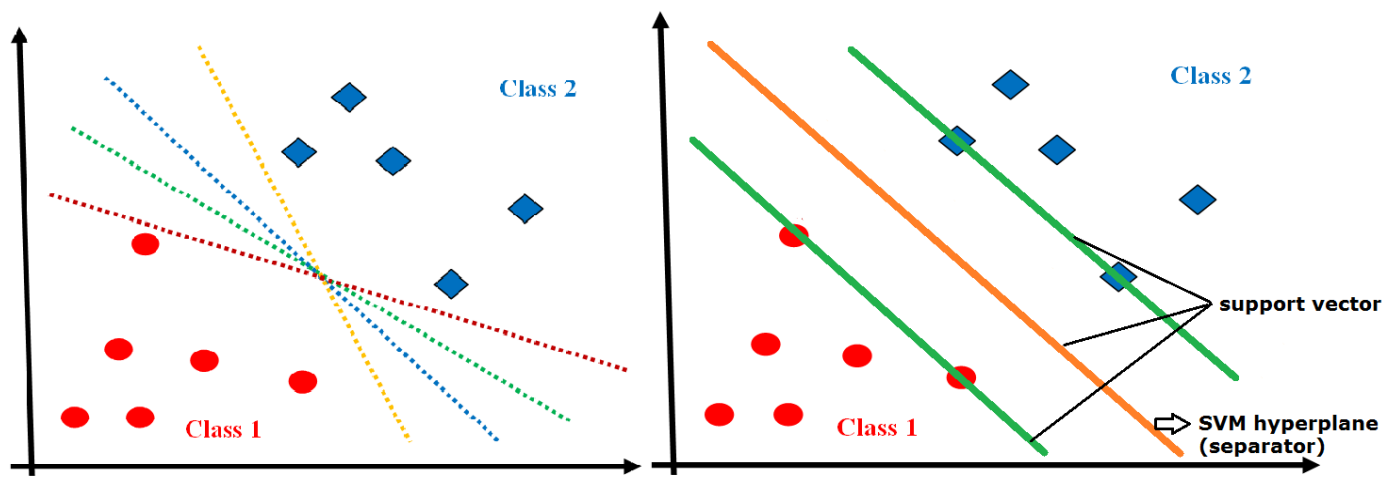

Figure 2. The SVM illustration finds the best hyperplane

Evaluation is conducted by testing the system that has been made. The system is then tested for accuracy. Accuracy is expressed by the number of documents that are classified correctly by the system [27]. The accuracy is calculated using three (3) and then tested using five (5) cross-validations. This technique runs five iterations of data sharing [28].

$$
\text { accuracy }=\frac{T P+T N}{T P+T N+F P+F N}
$$

where TP is the number of documents in a positive class classified correctly by the system while TN is the number of documents in the negative class classified correctly by the system. The number of positive class documents incorrectly classified by the system is stored in the $F N$ variable. On the other hand, the number of negative class documents incorrectly classified by the system is stored in the FP variable.

\subsection{Association and visualization}

The research uses a text association approach to determine the relationship between words in each positive review classification and negative reviews. The same process happens in obtaining information used as a reference for e-commerce parties and users/customers to find out what topics are being most discussed related to e-commerce 1, e-commerce 2, and e-commerce 3 [29],[30]. Eventually, such an association needs to be portrayed as a correlation. Furthermore, the correlation value is calculated using (4).

$$
r_{x y}=\frac{n \sum x_{i} y_{i}-\left(\sum x_{i}\right)\left(\sum y_{i}\right)}{\sqrt{\left\{n \sum x_{i}^{2}-\left(\sum x_{i}\right)^{2}\right\}\left\{n \sum y_{i}^{2}-\left(\sum y_{i}\right)^{2}\right\}}}
$$

where; $r_{x y}$ : the value of the correlation between variable $x$ and variable $y$

$n$ : number of data pairs $x$ and $y$

$\sum x_{i}$ : number of values in the variable $i=1,2,3, \ldots, n$

$\sum y_{i}$ : number of values in the variable $y$

$\sum x_{i}^{2}$ :square of the total value of the variable $x$

$\sum y_{i}^{2}$ : square of the total value of the variable $y$

$\sum x_{i} \sum y_{i}$ : number of multiplication results between the value of variable $x$ and variable $y$.

To make a visualization fishbone diagram is performed. It is addressed to visualize and identify the graphical description of all the causes of a problem. After obtaining the information from the previous text association method, the information is processed to solve the problem [31]. In identifying the problem cause, the information will be grouped according to the type of element. This grouping is based on elements of marketing tools abbreviated as 4Ps, namely: products, places, promotions, and prices. A mixed service adds Ps up to 7Ps with additional Ps: people, physical evidence, and process [32]. 


\section{RESULTS AND DISCUSSION}

\subsection{General description of users of e-commerce applications}

The number of reviews that entered the Google Play Store system from April 2020 to early June 2020. The number of e-commerce 1, e-commerce 2, and e-commerce 3 application review comparisons was 35\%: 33\%: $32 \%$ over the past three months. Out of 14,270 reviews, 4999 reviews on the e-commerce 1 application, 4661 reviews on the e-commerce 2 application, and 4610 reviews on the e-commerce 3 application. In the e-commerce 1 application, the number of reviews tends to be slightly in April, then in May, it increased significantly and then increased very dramatically in June. In the e-commerce 2 application, it was seen that most reviews were in April and May, but the review had decreased in June. Finally, the ecommerce 3 application shows the number of reviews not too different from the e-commerce 2 application in April and May and experienced a decrease in reviews that were not too significant in June. Figure 3 (a) displays the information review of e-commerce 1 , e-commerce 2 , and e-commerce 3 e-commerce mobile application applications from 1 April 2020 to 10 June2020.

Meanwhile, the comparison of e-commerce 1, e-commerce 2, and e-commerce 3 application user ratings in the application user review can be seen in Figure 3 (b). Ratings given by application users on the Google Play Store site have a scale of 1-5 sequentially with the categories "really do not like it", "do not like", "Not bad", "Like", and "really like". From the comparison of e-commerce 1 app user review ratings, as many as 1495 people claimed to "really like" and found a user review of 1974 people claiming to "really do not like it". On the e-commerce 2 app rating found 1152 people claimed to "really like" but found reviews "really do not like it" as many as 2134 people. In the e-commerce 3 application, there were 1954 reviews of people claiming to be "really like" and as many as 1597 people claiming "really do not like it".

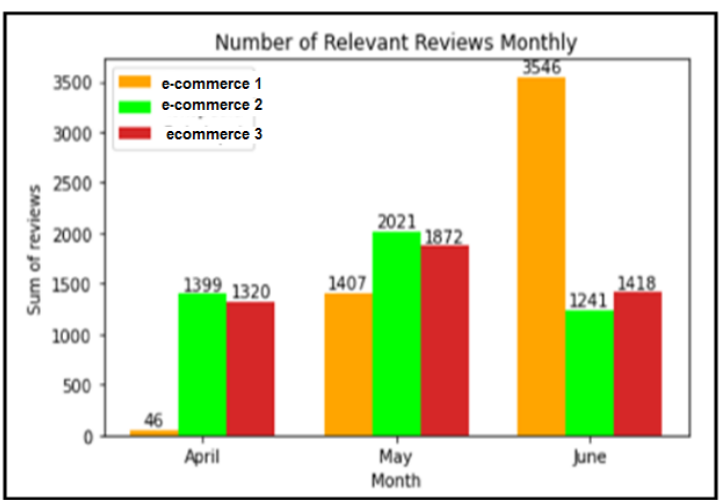

(a)

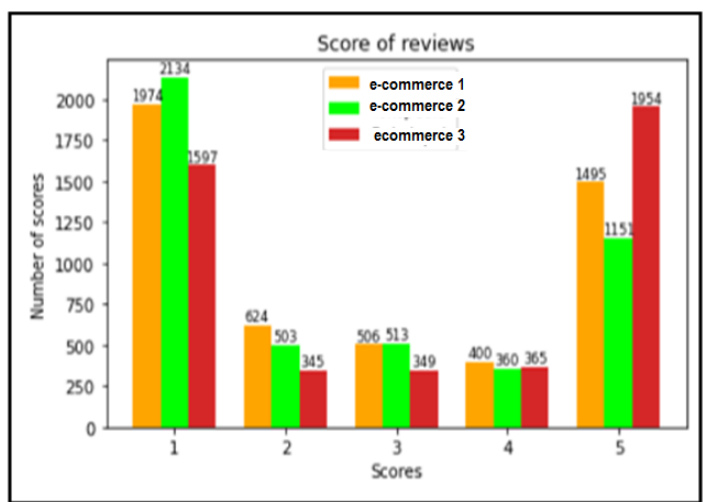

(b)

Figure 3. Comparison of the number of, (a) reviews, (b) rating

\subsection{Classification and accuracy of review data using the support vector machine method}

After the words are converted into vectors, they are all then fed through the preprocessing stage. In this stage, data is carried out by the process of cleansing, normalization, case-folding, tokenizing, filtering/stopword removal, and stemming. Subsequently, data is processed using a prediction algorithm, where it eventually falls into training data and test data. Training data and test data used are data that already have a class label, with a comparison of test data and training data is $80 \%: 20 \%$. The comparison can then be seen in Table 1 for each of the mobile e-commerce applications,namely e-commerce 1, e-commerce 2, e-commerce 3.

Table 1. Training data and test data

\begin{tabular}{ccccc}
\hline App & Classification & Training Data(80\%) & Test Data(20\%) & Total \\
\hline E-commerce 1 & Positive & 2770 & 693 & 3463 \\
& Negative & 1229 & 307 & 1536 \\
& Total & 3999 & 1000 & 4999 \\
E-commerce 2 & Positive & 2421 & 605 & 3026 \\
& Negative & 1308 & 327 & 1635 \\
& Total & 3729 & 932 & 4661 \\
E-commerce 3 3 & Positive & 2263 & 566 & 2829 \\
& Negative & 1425 & 356 & 1781 \\
& Total & 3688 & 922 & 4610 \\
\hline
\end{tabular}


Table 1 shows that the same comparison of training and testing data applied to all applications. The number of training data in the e-commerce 1 application is 3999 reviews while the test data are 1000 reviews, conclusively it adds up to 4999 reviews. On the other hand, the e-commerce 2 application bares the number of training data of 3729 reviews while the test data are 938 reviews giving 4661 review data. Finally, the e-commerce 3 application has the number of training data of 3688 reviews, and the test data are of 922 reviews, so that the total data is 4610 review data.In the classification process, the SVM algorithm uses the Kernel method to obtain the best accuracy classification. The Kernel method used is the linear, polynomial, $\mathrm{RBF}$, and sigmoid. Comparison of classifications using the e-commerce 1, e-commerce 2, and e-commerce 3 application review data yields each kernel method's accuracy is being as seen in Table 2:

Using the comparison of the results of several kernel methods shown in Table 2, shows that two of the three applications, namely e-commerce 1 and e-commerce 2 have the highest level of accuracy using the Linear Kernel method, compared to other kernel methods and for the e-commerce 3 application has the highest level of accuracy using the Sigmoid Kernel method compared to other Kernel methods. Thus, this classification process will use SVM, the Linear Kernel for the e-commerce 1 and e-commerce 2 applications, and the sigmoid kernel for the e-commerce 3 application. Evaluation of the model to find out the results of the classification accuracy employs the confusion matrix. This study uses cross-validation to test machine performance, informing classification so that 5 -fold cross-validation is formed. Based on Table 2, we select the best kernel method of each e-commerce for selecting the best accuracy of application review. The results of each machine learning experiment using the SVM method are being as seen in Table 3:

Table 2. Comparison of the accuracy of the Kernel method

\begin{tabular}{lccc}
\hline \multirow{2}{*}{ Kernel } & \multicolumn{3}{c}{ Accuracy } \\
\cline { 2 - 4 } & E-commerce 1 & E-commerce 2 & E-commerce 3 \\
\hline Linear & $87.70 \%$ & $88.30 \%$ & $85.79 \%$ \\
Polynomial & $70.80 \%$ & $66.45 \%$ & $69.96 \%$ \\
RBF & $81.90 \%$ & $81.46 \%$ & $84.71 \%$ \\
Sigmoid & $83.80 \%$ & $86.28 \%$ & $88.39 \%$ \\
\hline
\end{tabular}

In Table 3, five machine learning is performed at each application review. In the e-commerce 1 application review classification produces the highest accuracy value of $87.70 \%$ in machine learning 1 . In the e-commerce 2 application, the highest accuracy value in machine learning 3 is $88.30 \%$, and in the ecommerce 3 application, the highest accuracy value in machine learning 1 is $88.39 \%$.

Table 3. Comparison of machine learning accuracy values

\begin{tabular}{cccc}
\hline \multirow{2}{*}{ Machine Learning } & \multicolumn{3}{c}{ Accuracy } \\
\cline { 2 - 4 } & E-commerce 1(SVMlinear) & E-commerce 2(SVM linear) & E-commerce 3(SVM sigmoid) \\
\hline 1 & $87.70 \%$ & $84.46 \%$ & $88.39 \%$ \\
2 & $85.20 \%$ & $86.37 \%$ & $85.79 \%$ \\
3 & $87.40 \%$ & $88.30 \%$ & $83.73 \%$ \\
4 & $85.90 \%$ & $84.97 \%$ & $84.92 \%$ \\
5 & $86.99 \%$ & $86.05 \%$ & $85.25 \%$ \\
\hline
\end{tabular}

In Table 4, the confusion matrix, was formed using the support vector machine method. It shows the e-commerce 1 application review. It was obtained that the prediction results fallen in the negative class is of 163 negative reviews, with 131 reviews correctly classified. In contrast, the remaining 32 classifications are fallen into positive class. Predictions on the positive class of e-commerce 1 application review as many as 746 reviews are classified correctly into the positive class, while the remaining 91 reviews are categorized in the negative class of the total positive reviews of 837 . The accuracy value in the e-commerce 1 application review classification was $87.70 \%$, which means that from a total of 1000 review data as test data, there are 877 reviews correctly classified while the remaining 123 reviews fall into the wrong classification class. In the e-commerce 2 application review, the prediction results are obtained that in the negative class of the 272 negative reviews, there were 230 reviews correctly classified while the remaining 42 classified reviews were included in the positive class. Predictions on the positive class of e-commerce 2 app review as many as 593 reviews correctly classified into the positive class while the remaining 67 reviews entered the negative class of the total positive reviews as many as 660. The accuracy value in the e-commerce 2 application review classification is $88.30 \%$, which means that from a total of 932 review data as test data, there are 823 reviews correctly classified while the remaining 109 reviews fall into the wrong classification class.

Finally, the e-commerce 3 application review gives prediction results that in the negative class, from 238 negative reviews, 206 reviews are classified correctly, while the remaining 32 classified reviews are 
grouped in the positive class. Predictions on the positive class of e-commerce 3 application review are as many as 609 classified reviews correctly entered the positive class while the remaining 75 reviews miscategorized (negative class), while the total positive reviews are as many as 684. The accuracy value on the e-commerce 3 application review classification is $88.39 \%$, which means that of the total 922 review data as test data, there are 815 reviews correctly classified while the remaining 107 reviews fall into the wrong classification class. Shortly using this result, we can make interpretations to elaborate on some potential improvements in the future.

Table 4.Confusion matrix

\begin{tabular}{|c|c|c|c|}
\hline \multirow{2}{*}{ App } & \multirow{2}{*}{ Prediction } & \multicolumn{2}{|c|}{ Accuracy } \\
\hline & & Positive & Negative \\
\hline \multirow[t]{3}{*}{ E-commerce 1} & Positive & 746 & 32 \\
\hline & Negative & 91 & 131 \\
\hline & Accuracy & \multicolumn{2}{|c|}{$87.70 \%$} \\
\hline \multirow[t]{3}{*}{ E-commerce 2} & Positive & 593 & 42 \\
\hline & Negative & 67 & 230 \\
\hline & Accuracy & \multicolumn{2}{|c|}{$88.30 \%$} \\
\hline \multirow[t]{3}{*}{ E-commerce 3} & Positive & 609 & 32 \\
\hline & Negative & 75 & 206 \\
\hline & Accuracy & \multicolumn{2}{|c|}{$88.39 \%$} \\
\hline
\end{tabular}

\subsection{Association factors that influence user perceptions of e-commerce applications}

Rely on the word association method, this study will use negative reviews from the previous classification results. Negative reviews will usually be a very influential factor in the user's perception of using/buying and even providing input in reviews of services or products offered. In the negative ecommerce 1 review classification results obtained, some of the most words that appear with topics that are considered relevant as negative sentiments include the word "problem" with a frequency of 1267 times, "interference" as much as 1141 times, and "long" 934 times. Next, look for associations between words that often appear together that refer to the discussion, which can be seen in Table 5. Table 5 also shows the relationship between words in negative reviews, and these words are the topics most frequently discussed by users in their review. Table 5 also shows the relationship between words in negative reviews; users in their reviews most frequently discuss these words. One of the results is shown in Table 5 (a). This table contains words associated with "account" provides information that it is difficult to log in even though the account used is correct, but it still fails even though it has been done repeatedly; consequently, the user is too late verifying e-commerce 1 pay, which makes him/her fined a penalty. The other result is represented in Table 5 (b). It contains the negative classification results of e-commerce 2 . It is obtained from some of the most common words, including the word "bad" with a frequency of 833 times, "canceled" 524 times, and "disappointed" 515 times. Table 5 (b) shows the relationship between words on negative reviews, and these words are the topics most frequently discussed by users in their reviews. One result is that words related to "upload" provide information on the slowness and sometimes fail to upload images or information about the seller's products. This incident repeatedly occurs. Therefore the seller's store becomes alienated due to the lack of coming buyers.In the classification results of e-commerce 3 negative reviews, it was obtained that some of the words that appeared the most included words "problems" with a frequency of 815 times, "disappointed" 711 times, and "bad" as many as 590 times. Table 5 (c) shows the relationship between words in negative reviews, and these words are the topics most frequently discussed by users in their reviews. One result is that words related to "product" provide information about e-commerce 3 users' complaints about packaging purchases through e-commerce 3, which are untidy and cluttered. The goods received become damaged when making returns to the seller does not respond, resulting in buyers feeling a loss.

\subsection{The proposed solution to solving problems e-commerce using the results of the fishbone diagram}

The text association method shows that information extraction on negative classes often complained of products, applications, updates, servers, chat, accounts, transactions, uploads, promos, vouchers, balances, and upgrades. This information can be considered a factor that can affect users' perceptions of writing reviews. Based on the text association results, information can be obtained about complaints and problems that occur, directly involving the developer, seller, and buyer/user related to negative reviews in e-commerce e-commerce 1 , e-commerce 2 , and e-commerce 3 . The information is the factors that can influence the user's perception of e-commerce 1, e-commerce 2, and e-commerce 3 e-commerce services/products. Furthermore, 
it was grouped using significant factors that are extracted from the review. Four factors are related to processes, products, and people, and promotions.

Table 5. Text association in negative sentiment classes, (a) e-commerce 1, (b) e-commerce 2, (c) e-commerce 3 (a)

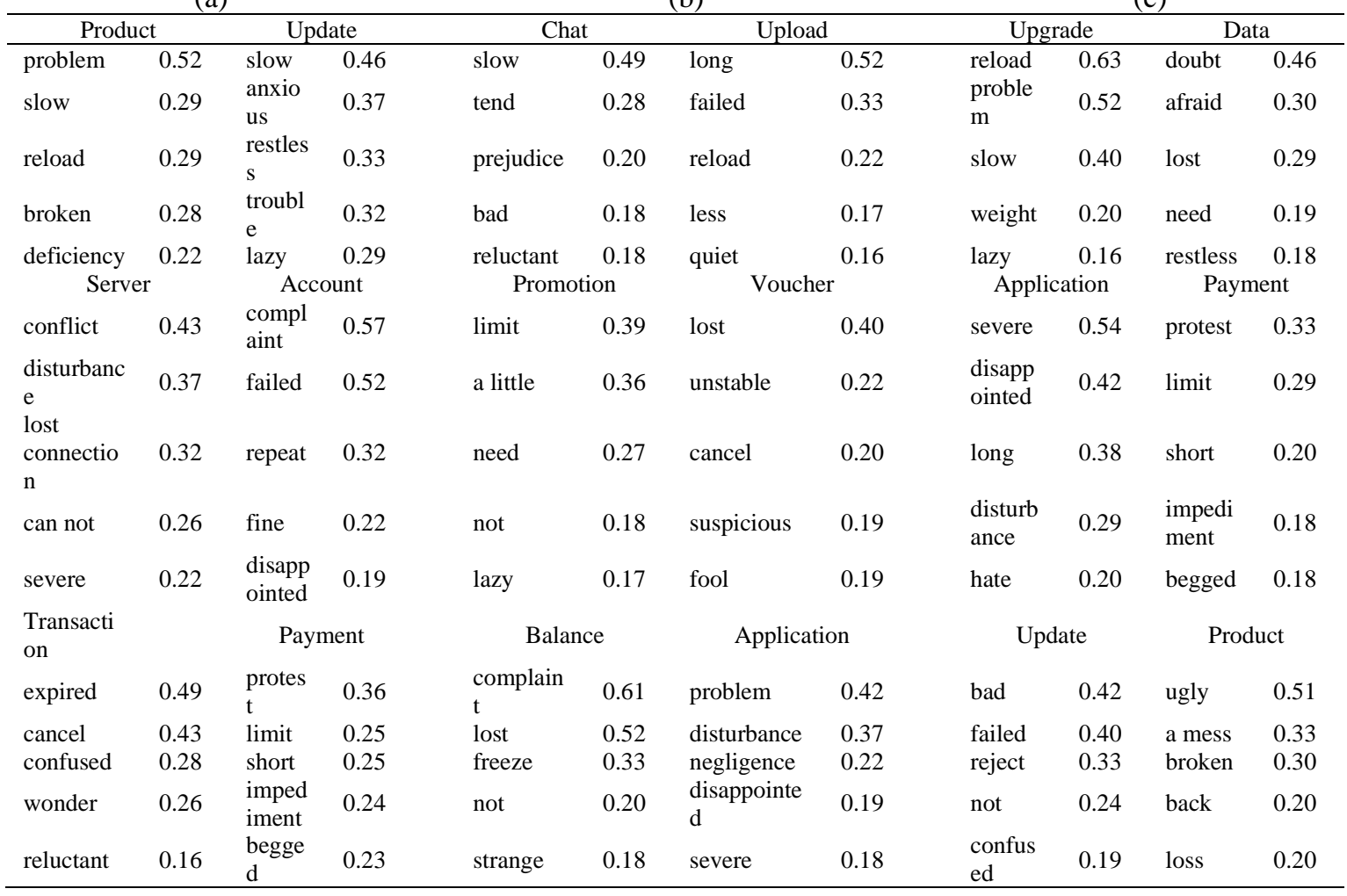

Tables 6-8 show that the significant factor is different. This study found complaints/problems in ecommerce 1 and e-commerce 3 contain factors processes, products, people, while e-commerce 2 contains 4 factors, ie. processes, products, people, and promotions. The next step is to create a solution to the problem that occurs using a fishbone diagram. Based on the analysis of cause-effect diagrams (fishbone diagrams), 23 common problems were obtained from the e-commerce 1 application: e-commerce 2 as many as eight problems, and e-commerce 3 seven problems. The identification results from negative reviews of ecommerce 1, e-commerce 2, and e-commerce 3 users are classified into 4P factors that must be considered, namely process, product, people, and promotion. The design results to resolve the problems that occur in ecommerce 1 e-commerce can be seen in Table 6, for e-commerce e-commerce 2 can be seen in Table 7, and for e-commerce, e-commerce 3 can be seen in Table 8 as shown in.

Table 6. E-commerce 1 application troubleshooting plans

\begin{tabular}{|c|c|c|}
\hline Factors & Problem & Problem Solution \\
\hline \multirow{2}{*}{ Process } & $\begin{array}{l}\text { The system experienced an } \\
\text { error after the update }\end{array}$ & $\begin{array}{l}\text { For E-Commerce 1, it is recommended that before launching the latest version of the } \\
\text { application, please be more careful in developing and testing it before launching it to } \\
\text { users so as not to cause errors in the latest updates. }\end{array}$ \\
\hline & $\begin{array}{l}\text { Canceling orders unilaterally } \\
\text { without confirmation }\end{array}$ & $\begin{array}{l}\text { For the buyer to follow the Standard Operating Procedure (SOP) in E-Commerce 1, what } \\
\text { if the item have already been paid, so that they can be returned immediately and for the } \\
\text { E-Commerce } 1 \text { to evaluate the actions of the seller or buyer if they often cancel one side, } \\
\text { so as not to harm the parties concerned. }\end{array}$ \\
\hline
\end{tabular}


Table 6. E-commerce 1 application troubleshooting plans (continue)

\begin{tabular}{lll}
\hline Factors & Problem & Problem Solution \\
\hline Process & $\begin{array}{l}\text { The time of payment is } \\
\text { inadequate. }\end{array}$ & $\begin{array}{l}\text { For E-Commerce 1 to extend the payment times, so the buyer does not have to feel the } \\
\text { rush of making a payment, and the user can turn on the notification of the remaining } \\
\text { payment time to be reminded. }\end{array}$ \\
Feople & $\begin{array}{l}\text { Failed to log into the } \\
\text { application } \\
\text { review the incoming email and password. } \\
\text { Get a sufficient/sanction } \\
\text { because of the difficulty of } \\
\text { accessing the application. }\end{array}$ & \\
\hline
\end{tabular}

Table 7. E-commerce 2 application troubleshooting plans

\begin{tabular}{|c|c|c|}
\hline Factors & Problem & Problem Solution \\
\hline Product & Interference after updating & $\begin{array}{l}\text { For E-Commerce 2, it is recommended that before launching the latest version of the } \\
\text { application, please be more careful in developing and testing it before launching it to users } \\
\text { so as not to cause errors in the latest updates. }\end{array}$ \\
\hline Process & $\begin{array}{l}\text { Failed to upload product } \\
\text { photos and information }\end{array}$ & For E-Commerce 2 to review or evaluate the product upload service-renewal system. \\
\hline \multirow[t]{3}{*}{ People } & Loss of funds in balance & $\begin{array}{l}\text { E-Commerce } 2 \text { should review the user's transaction history, and if there is a mistake or } \\
\text { error in the system, return the funds in the balance and explain the information to the user. }\end{array}$ \\
\hline & Fund freezing in balance & $\begin{array}{l}\text { For users to find out information on why the funds in the balance can be frozen by } \\
\text { contacting the customer service to be given a more advanced explanation, it may be that the } \\
\text { user gets sanctions/reprimands based on violating E-Commerce } 2 \text { 's order. }\end{array}$ \\
\hline & $\begin{array}{l}\text { Tend to cancel orders } \\
\text { because of late responding }\end{array}$ & $\begin{array}{l}\text { For sellers and buyers to turn on notification notifications to immediately receive and } \\
\text { respond to messages received. }\end{array}$ \\
\hline Promotion & $\begin{array}{l}\text { The voucher code is just the } \\
\text { lure }\end{array}$ & $\begin{array}{l}\text { For E-Commerce } 2 \text { and sellers, it is better if the vouchers shown are not valid for use by } \\
\text { buyers; please remove them. }\end{array}$ \\
\hline
\end{tabular}

Table 8. E-commerce 3 application troubleshooting plans

\begin{tabular}{|c|c|c|}
\hline Factors & Problem & Problem Solution \\
\hline \multirow[t]{3}{*}{ Product } & $\begin{array}{l}\text { The item suffered damage } \\
\text { after receipt }\end{array}$ & $\begin{array}{l}\text { E-Commerce } 3 \text { should put more emphasis on the seller. It is about the Standard Operating } \\
\text { Procedure (SOP)for the safety of the item ordered when sending the item. It is used to } \\
\text { minimize the damage to the shipment. }\end{array}$ \\
\hline & $\begin{array}{l}\text { Seller does not respond to } \\
\text { a damaged item }\end{array}$ & $\begin{array}{l}\text { The buyer should submit a complaint to the customer service to be followed up and for the E- } \\
\text { Commerce } 3 \text { to evaluate the seller and impose sanctions if it is proven to send the item in a } \\
\text { damaged condition. }\end{array}$ \\
\hline & $\begin{array}{l}\text { Interference with } \\
\text { application }\end{array}$ & $\begin{array}{l}\text { E-Commerce } 3 \text { should be able to research and update the application and eliminate } \\
\text { bugs/annoyances. }\end{array}$ \\
\hline \multirow[t]{2}{*}{ Process } & Failed to upload product & $\begin{array}{l}\text { E-Commerce } 3 \text { should conduct a review or evaluation of the product upload-service renewal } \\
\text { system to function normally again. }\end{array}$ \\
\hline & $\begin{array}{l}\text { The refund process is slow } \\
\text { and complicated. }\end{array}$ & $\begin{array}{l}\text { E-Commerce } 3 \text { should be able to innovate, especially in the refund service, to become much } \\
\text { more efficient. }\end{array}$ \\
\hline People & $\begin{array}{l}\text { User data is lost after the } \\
\text { application is updated } \\
\text { User data were stolen. }\end{array}$ & $\begin{array}{l}\text { E-Commerce } 3 \text { should be able to backup data and carry out strict security of the private user } \\
\text { data. It covers from sellers, buyers to E-Commerce } 3 \text { partners who are registered as users } \\
\text { therein. }\end{array}$ \\
\hline
\end{tabular}

\section{CONCLUSION}

This study aims to explore the critical factors that exist in e-commerce. The data is grabbed from the e-commerce review data. Text mining is applied with the help of a support vector machine used to identify sentiments for further processing. The results show that the model can separate sentiment and associate it with related factors. The SVM method's sentiment classification results show that all the accuracy of sentiment classification is more than $87 \%$. Furthermore, the text association method used shows that information extraction on negative classes often complained of products, applications, updates, servers, chat, accounts, transactions, uploads, promos, vouchers, balances, and upgrades. This information can be considered as a factor that can affect users' perceptions of writing reviews. Finally, our results show that there are 23 common problems were obtained from the e-commerce 1 application. Moreover, it can be grouped into four significant, i.e., factor process, product, people, and promotion, although the results are promising. Further research is still needed to improve the results, especially on interpreting text data with specific purposes, so that the aspects of positive sentiment can be associated and grouped for improving customer satisfaction. 


\section{ACKNOWLEDGEMENTS}

The author would like to thank to the Magister Informatika, Program Pascasarjana, UniversitasAtma Jaya Yogyakartafor the financial support to our research project. I would also like to express my gratitude to all members of Data Engineering and Information System Research Group, Informatics Department, Universitas Atma Jaya Yogyakartafor providing time toconduct our research.

\section{REFERENCES}

[1] S. P. Eslami and M. Ghasemaghaei, "Effects of online review positiveness and review score inconsistency on sales: A comparison by product involvement," Journal of Retailing and Consumer Services, vol. 45, pp. 74-80, August2018, doi: 10.1016/j.jretconser.2018.08.003.

[2] M. Geetha, P. Singha and S. Sinha, "Relationship between customer sentiment and online customer ratings for hotelsAn empirical analysis," Tourism Management, vol. 61, pp. 43-54, 2017, doi: 10.1016/j.tourman.2016.12.022.

[3] D. Plotkina and A. Munzel, "Delight the experts, but never dissatisfy your customers! A multi-category study on the effects of online review source on intention to buy a new product," Journal of Retailing and Consumer Services, vol. 29, pp. 1-11, 2016, doi: 10.1016/j.jretconser.2015.11.002.

[4] J. Guo, X. Wang and Y. Wu, "Positive emotion bias: Role of emotional content from online customer reviews in purchase decisions," Journal of Retailing and Consumer Services, vol. 52, p. 101891, 2020, doi: 10.1016/j.jretconser.2019.101891.

[5] J. Kim and S. J. Lennon, "Effects of reputation and website quality on online consumers' emotion, perceived risk and purchase intention: Based on the stimulus-organism-response model," Journal of Research in Interactive Marketing, vol. 7, no. 1, pp. 33-56, 2013, doi: 10.1108/17505931311316734.

[6] G. Wagner, H. Schramm-Klein and M. Schu, "Determinants and Moderators of Consumers' Cross-Border Online Shopping Intentions," Marketing: ZFP-Journal of Research and Management, vol. 38, no. 4, pp. 214-227, 2016, doi: 10.15358/0344-1369-2016-4-214

[7] S. Moon, Y. Park and Y. S. Kim, "The impact of text product reviews on sales," European Journal of Marketing, vol. 48, no. 11-12, pp. 2176-2197, 2014, doi: 10.1108/EJM-06-2013-0291.

[8] T. Rungvithu and C. Kerdvibulvech, "Conversational Commerce and CryptoCurrency Research in Urban Office Employees in Thailand," International Journal of e-Collaboration (IJeC), vol. 15, no. 3, pp. 34-48, 2019, doi: 10.4018/IJeC.2019070103.

[9] Y. Y. Maryeni, R. Govindaraju, B. Prihartono and I. Sudirman, "Technological and organizational factors influencing the e-commerce adoption by Indonesian SMEs," 2012 IEEE International Conference on Management of Innovation \& Technology (ICMIT), 2012, pp. 436-441, doi: 10.1109/ICMIT.2012.6225845.

[10] T. M. Nisar, G. Prabhakar, P. V. Ilavarasan and A. M. Baabdullah, "Up the ante: Electronic word of mouth and its effects on firm reputation and performance," Journal of Retailing and Consumer Services, vol. 53, p. 101726, 2020, doi: 10.1016/j.jretconser.2018.12.010.

[11] A. S. Rathor, A. Agarwal and P. Dimri, "Comparative Study of Machine Learning Approaches for Amazon Reviews,” Procedia computer science, vol. 132, pp. 1552-1561, 2018, doi: 10.1016/j.procs.2018.05.119.

[12] M. Haddoud, A. Mokhtari, T. Lecroq and S. Abdeddaïm, "Combining supervised term-weighting metrics for SVM text classification with extended term representation,' Knowledge and Information Systems, vol. 49, no. 3, pp. 909931, February 2016, doi: 10.1007/s10115-016-0924-1.

[13] M. M. Mirończuk and J. Protasiewicz, "A recent overview of the state-of-the-art elements of text classification,"Expert Systems with Applications, vol. 106, pp. 36-54,September 2018, doi: 10.1016/j.eswa.2018.03.058.

[14] L. Oneto, F. Bisio, E. Cambria and D. Anguita, "Statistical Learning Theory and ELM for Big Social Data Analysis," in IEEE Computational Intelligence Magazine, vol. 11, no. 3, pp. 45-55, Aug. 2016, doi: 10.1109/MCI.2016.2572540.

[15] A. A. Lutfi, A. E. Permanasari and S. Fauziati, "Corrigendum: Sentiment Analysis in the Sales Review of Indonesian Marketplace by Utilizing Support Vector Machine," Journal of Information Systems Engineering and Business Intelligence, vol. 4, no. 1, pp. 57-64, 2018, doi: 10.20473/jisebi.4.2.169.

[16] P. Vijayaragavan, R. Ponnusamy and M. Aramudhan, "An optimal support vector machine based classification model for sentimental analysis of online product reviews," Future Generation Computer Systems, vol. 111, pp. 234-240, 2020, doi: 10.1016/j.future.2020.04.046.

[17] D. B. Setyohadi, S. Kusrohmaniah, S. B. Gunawan, Pranowo and A. S. Prabuwono, "Galvanic skin response data classification for emotion detection," International Journal of Electrical and Computer Engineering (IJECE), vol. 8, no. 5, pp. 4004-4014, October 2018, doi: 10.11591/ijece.v8i5.pp4004-4014.

[18] O. Oyebode, F. Alqahtani and R. Orji, "Using Machine Learning and Thematic Analysis Methods to Evaluate Mental Health Apps Based on User Reviews," in IEEE Access, vol. 8, pp. 111141-111158, 2020, doi: 10.1109/access.2020.3002176.

[19] D. Suganthi and A. Geetha, "Twitter Sentiment Analysis on GST tweets using R tool," International Journal of Scientific Research in Computer Science, Engineering and Information Technology, vol. 2, no. 5, pp. 793-796, 2017.

[20] E. Sutoyo and A. Almaarif, "Twitter sentiment analysis of the relocation of Indonesia's capital city," Bulletin of Electrical Engineering and Informatics (BEEI), vol. 9, no. 4, pp. 1620-1630, August 2020, doi: 10.11591/eei.v9i4.2352. 
[21] N. Hu, N. Sian and S. K. Reddy, "Ratings lead you to the product, reviews help you clinch it? The mediating role of online review sentiments on product sales," Decision support systems, vol. 57, pp. 42-53, 2014, doi: 10.1016/j.dss.2013.07.009.

[22] E. Choi, J. Lyu, J. Park and H. Y. Kim, "Statistical methods used in articles published by the journal of periodontal and implant science," Journal of periodontal \& implant science, vol. 44, no. 6, pp. 288-292, 2014, doi: 10.5051/jpis.2014.44.6.288.

[23] B. Olabenjo, "Applying Naive Bayes Classification to Google Play Apps Categorization," arXiv preprint arXiv:1608.08574, December 2016.

[24] B. M. Jadav and V. B. Vaghel, "Sentiment Analysis using Support Vector Machine based on Feature Selection and Semantic Analysis," International Journal of Computer Applications, vol. 146, no. 13, pp. 26-30, 2016.

[25] B. E. Boser, V. N. Vapnik and I. M. Guyon, " A Training Algorithm Margin for Optimal Classifiers," in Proceedings of the fifth annual workshop on Computational learning theory, pp. 144-152, July 1992, doi: 10.1145/130385.130401.

[26] G. N. Kouziokas, "SVM kernel based on particle swarm optimized vector and Bayesian optimized SVM in atmospheric particulate matter forecasting," Applied Soft Computing, vol. 93, p. 106410, 2020, doi: 10.1016/j.asoc.2020.106410.

[27] L. Yang, Y. Li, J. Wang and R. S. Sherratt, "Sentiment Analysis for E-Commerce Product Reviews in Chinese Based on Sentiment Lexicon and Deep Learning," in IEEE Access, vol. 8, pp. 23522-23530, 2020, doi: 10.1109/ACCESS.2020.2969854.

[28] Y. Jung, "Multiple predicting K-fold cross-validation for model selection," Journal of Nonparametric Statistics, vol. 30, no. 1, pp. 197-215, 2018, doi: 10.1080/10485252.2017.1404598.

[29] M. Kaur and S. Kang, "Market Basket Analysis: Identify the Changing Trends of Market Data Using Association Rule Mining," Procedia computer science, vol. 85, pp. 78-85, 2016, doi: 10.1016/j.procs.2016.05.180.

[30] S. Jabri, A. Dahbi and T. Gadi, "A graph-based approach for text query expansion using pseudo relevance feedback and association rules mining," International Journal of Electrical and Computer Engineering (IJECE), vol. 9, no. 6, pp. 5016-5023, December 2019, doi: 10.11591/ijece.v9i6.pp5016-5023.

[31] M. Coccia, "The Fishbone diagram to identify, systematize and analyze the sources of general purpose technologies," Journal of Social and Administrative Sciences, vol. 4, no. 4, pp. 291-303, doi: $10.1453 /$ jsas.v4i4.1518.

[32] Su-Mei Lin, "Marketing mix (7P) and performance assessment of Western fast food industry in Taiwan: An application by associating DEMATEL (Decision making Trial and Evaluation Laboratory) and ANP (Analytic Network Process)," African Journal of Business Management, vol. 5, no. 26, pp. 10634-10644, 2011, doi: 10.5897/ajbm11.894.

\section{BIOGRAPHIES OF AUTHORS}
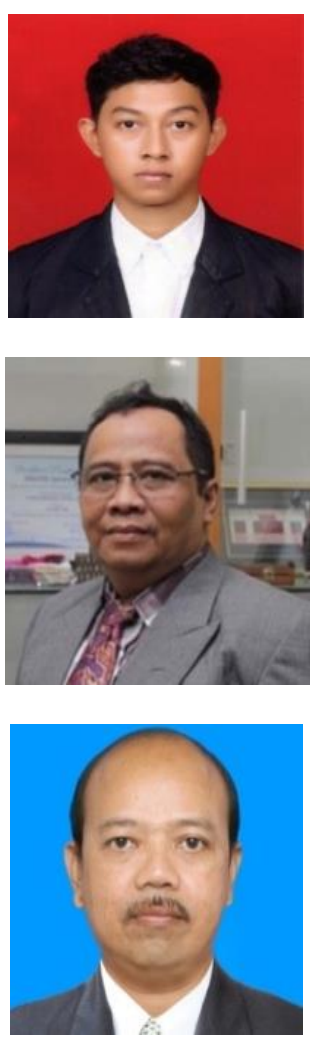

Irvan Krisna Arsad born in Jayapura 1996. Received a bachelor's degree in 2014 at Cenderawasih University, Department of Economic and Business. Currently pursuing a master's degree in Magister Informatika, Universitas Atma Jaya Yogyakarta. His current interests are in the fields of data analytics and parallel programming.

Djoko Budiyanto Setyohadi received the B.E. degree in Electrical Engineering from Universitas Gadjah Mada, Yogyakarta, Indonesia in 1990, and the M.Eng. degree in Computer Science, Information Management from the Asian Institute of Technology, Bangkok, Thailand, in 1998 and the $\mathrm{PhD}$ degree in Computer Science from University Kebangsaan Malaysia in 2014. He is Professor of Informatics Departement at the Faculty of Industrial Engineering, Universitas Atma Jaya Yogyakarta. His current research interests include Information System, Human-Computer Interface, and Data Engineering.

Paulus Mudjihartono is an Associate Professorof Informatics Department Universitas Atma Jaya Yogyakarta, Indonesia. His Bachelor Degree is from Electrical Engineering of Universitas Gadjah Mada, Yogyakarta, Indonesia in 1993. In 2020 he got a Master Degree in Informatics from InstitutTeknologi Bandung. He passed his doctoral degree in 2019 majoring in Computer Science from the Assumption University of Thailand. His research focus is on metaheuristic algorithms, machine learning, and parallel computation. His several last publications are concerning modified PSO, cluster analysis and the implementation of CUDA. 